\title{
Earth has not anything to show more fair....
}

Please forgive a personal reflection on transport and health. This morning I have had the privilege of cycling to work (an electric bike) along dedicated cycle paths embedded within a city that have taken me through woods, along river paths in beautiful autumn sunshine, observing birds and listening to their song. As Wordsworth so memorably wrote:

"Dull would he be of soul who could pass by

A sight so touching its majesty:

This City now doth like a garment wear

The beauty of the morning: silent, bare" (1)

Where in our discourse about active travel is this notion of wellbeing, of joy, and of connection with nature? Perhaps we need to pay more attention to the emotional and psychological impacts of walking and cycling as methods of transport. This might provide some sort of counterbalance to the huge creative endeavor undertaken to persuade us of the positive and aspirational benefits of driving different types of automobiles on our self-image and happiness in the promotion undertaken by the car industry. Douglas (2) argues that private cars share many characteristics with tobacco and could be regarded as the archetypal ecological risk, and for the need for the public health community to advocate strongly for effective policies to reduce care use and increase active travel. Some of these policies may be controversial, such as the right (or not) to have free parking at the workplace. Evidence suggests however that some interventions have a sudden and dramatic impact on active travel rates; the introduction of a workplace travel policy which limited parking places in a university for staff and students living close to their workplace was associated with a significant increase in the proportion both cycling and walking to work and a $70 \%$ were meeting $80 \%$ of their recommended physical activity goals through active travel (3). The important role of active transport in physical activity is again highlighted in this edition by Shaw et al (4), highlighted as Editor's Choice, in 
New Zealand who found that people who walk or cycle to their main activity are $76 \%$ more likely to meet physical activity guidelines. Thus we need to look seriously at policies that impact on these rates, including controversial areas such as workplace parking restrictions. There is also further evidence of a substantial decline of patterns in active travel to school in children compared to their parents (5) in this edition.

Changing behaviour is complex, and the behaviour change model (6) describes a number of key factors affecting behaviour change- including capability, opportunity and motivation. Opportunity is a key driver of travel behaviour. We know that provision of cycling infrastructure (7) is associated with increases in use, with a delay as individuals take time to adjust. There is also good evidence that the form and structure of the built environment influences behaviour, with studies showing that when individuals move into an environment designed to support walking, peoples' behaviour changes (8). Lee (9)in this edition demonstrates that local shops encourage short walking trips and avoid "tripchaining" whereby people undertake several tasks in one long trip; this has implications for the design of new developments and urban form. As the evidence accumulates that urban design and the built environment impact on behaviour there is need to ensure that new developments are fit for purpose, and that the inequalities inbuilt into our existing environment with respect to infrastructure as outlined by Fuller et al are addressed (10).

\section{Professor Selena Gray}

Associate Editor

\section{References}

1.William Wordsworth Composed upon Westminster Bridge, Sept $3^{\text {rd }} 1802$

2. Margaret J. Douglas, Stephen J. Watkins, Dermot R. Gorman and Martin Higgins. Are cars the new tobacco? J Pub Med 2011;33(2)160-169.

3. Fox K, Brockman JR. Physical activity by stealth? The potential health benefits of a workplace transport plan Public Health. 2011 Apr;125(4):210-6. doi:

10.1016/j.puhe.2011.01.005. Epub 2011 Mar 31. 
4. Caroline Shaw, Michael Keall, Hayley Guiney, What modes of transport are associated with higher levels of physical activity? Cross-sectional study of New Zealand adults, Journal of Transport \& Health (this edition)

5. Mitchie S, Atkins L, West R. The Behaviour Change Wheel http://www.behaviourchangewheel.com \{accessed 27th Oct 2017]

6. Bhosale, J, Duncan S, Schofield G et al. Intergenerational change in children's independent mobility and active transport in New Zealand children and parents. Journal of Transport and Health (this edition)

7. Heinen E, Ogilvie D. Variability in baseline travel behaviour as a predictor of changes in commuting by active travel, car and public transport: a natural experimental study Journal of Transport \& Health; 2016: 3,;7-85

8. Matthew W. Knuiman Hayley E. Christian Mark L. Divitini Sarah A. FosterFiona C. Bull Hannah M. Badland Billie Giles-Corti. A Longitudinal Analysis of the Influence of the Neighborhood Built Environment on Walking for Transportation: The RESIDE Study. American Journal of Epidemiology, 2014; 180: $453-461$

9. Jeongwoo Lee, Sylvia Y. He, Dong Wook Sohn, Potential of converting short car trips to active trips: The role of the built environment in Jeongwoo Lee, Sylvia Y. He, Dong Wook Sohn, Potential of converting short car trips to active trips: The role of the built environment in tour-based travel, Journal of Transport \& Health (this edition)

10. Daniel Fuller, Meghan Winters, Income inequalities in Bike Score and bi Daniel Fuller, Meghan Winters, Income inequalities in Bike Score and bicycling to work in Canada, Journal of Transport \& Health (this edition) 